\title{
O INCONSCIENTE NA INTERPRETAÇÃO CLÍNICA ANALÍTICO-COMPORTAMENTAL
}

\author{
The Unconscious According to the Clinical Behavior Analysis Interpretation
}

El Inconsciente en la Interpretación Clínica Conductual

JoCElaine Martins da Silveira

LÁZARO DE ALMEIDA

\begin{abstract}
Resumo: O presente trabalho teve o objetivo de descrever as bases da interpretação clínica analítico-comportamental do inconsciente. Textos de B. F. Skinner que abordaram o tema do inconsciente foram consultados e examinados, assim como de clínicos em Análise do Comportamento. O exame da literatura indicou que, de acordo com a Análise Comportamental, há duas principais condições nas quais o termo inconsciente é empregado por certas tradições teóricas em Psicologia. Ambas as condições dependem de um ambiente social e verbal que promove a aprendizagem de comportamentos autodescritivos e que ensina também uma classe de fuga/esquiva de tais descrições. A primeira condição refere-se à inconsciência devida à falta de exposição a um ambiente verbal gerador de conhecimento sobre o que se fez, o que se está fazendo, o que se tende a fazer ou sobre as variáveis controladoras de um dado comportamento. Uma segunda condição em que o termo inconsciente é usado está mais estreitamente ligada ao que certas teorias psicológicas chamariam de inconsciente reprimido e diz respeito à exposição à contingências punitivas. Na clínica analítico-comportamental, as duas condições são analisadas, mas grande ênfase é dada à segunda, ou seja, àquela que produz uma classe de fuga/esquiva de tatear comportamentos puníveis.
\end{abstract}

Palavras-chave: Análise comportamental clínica; Inconsciente; Behaviorismo radical.

Abstract: The aim of this article was to describe the clinical behavior analysis background related to the topic unconsciousness. In order to understantd the topic, some B. F. Skinner's publicatons about unconscious were examined, as well as some publications in the clinical behavior analysis field. Results indicated that, according to Behavior Analysis, there are two main conditions on which the term unconscious is applied in certain theoretic traditions in Psychology. Both conditions depend on a social-verbal environment that teaches self-descriptive behaviors and also teachs the response class of avoiding such descriptions. The first condition relies on the unconsciousness caused by the lack ou poor exposure of a verbal environment which would promote the knowlege about what one has done, what one is doing, what one tends to do or about the controling variables of a given behavior. The second condition in which the term unconscious is used is closely related to what certain theories would call repressed unconscious and it is produced by punishing contingencies. In the clinical behavior analysis, these both conditions are analysed, but the sencond type is specially focused, that is, those conditions that produce the response class of escaping/avoiding the de tacts of punishable behaviors.

Keywords: Clinical behavior analysis; Unconsciousness; Radical behaviorism.

Resumen: El presente trabajo tuvo como objetivo describir las bases de la interpretación clínica conductual del inconsciente. Textos de B. F. Skinner que abordaron el tema del inconsciente fueron consultados y examinados, así como de clínicos conductistas. La revisión de la literatura indicó que, de acuerdo con los conductistas hay dos condiciones principales en las cuales el término inconsciente es empleado por ciertas tradiciones teóricas en Psicología. Ambas condiciones dependen de un ambiente social y verbal que promuevan el aprendizaje de comportamientos auto descriptivos y que también enseñen una clase de escape/ evitación de esas descripciones. La primera condición se refiere a la inconsciencia debido a la falta de exposición a un ambiente verbal generador de conocimiento sobre el que se hizo o se está haciendo, o que se tiende a hacer o sobre las variables controladoras de un determinado comportamiento. Una segunda condición en el cual el término inconsciente es usado está más estrechamente ligado a ciertas teorías psicológicas que lo llamarían de inconsciente reprimido y se refiere a la exposición de contingencias de castigo. En el análisis conductual, las dos condiciones son analizadas, dando mayor importancia a la segunda, o sea, aquella que produce una clase de escape/evitación de tantear el comportamiento de castigo.

Palabras-clave: Análisis conductual clínica; Inconsciente; Conductismo radical. 


\section{Introdução}

Escrever sobre o inconsciente na Análise do Comportamento pode parecer, em um primeiro momento, estranho. Entretanto, se o tema foi tão importante na formação de escolas de pensamento psicológico, seria, no mínimo, prudente indagar sobre sua contribuição .

No intuito de buscar compreender o inconsciente no contexto da Análise do Comportamento (AC), mais especificamente, no contexto da clínica analítico-comportantal, o presente artigo examinou o emprego do termo "inconsciente" em alguns textos de B. F. Skinner. Considerou-se ainda o tratamento que os clínicos analistas comportamentais deram ao tema.

A primeira parte do artigo pretendeu justificar a necessidade de discutir o inconsciente na perspectiva da AC. Em seguida, questionou-se a capacidade da análise comportamental para tratar termos oriundos de outras tradições teóricas. A terceira parte tratou do inconsciente na Análise do Comportamento fundamentando-se em textos de B. F. Skinner e recorrendo também à sistematização proposta por Abib (2007). A quarta parte abordou a noção de inconsciente no contexto clínico e possibilidades de manejo.

Os textos de B. F. Skinner publicados em livros foram consultados. Foram examinados os excertos que continham os seguintes termos: consciente, inconsciente, consciência, inconsciência, comportamento autodescritivo, auto-observação, conhecer, conhecimento, autoconhecimento, ver, e ver vendo. Desse procedimento, resultaram textos extraídos dos livros Sobre o Behaviorismo (1974), Contingências do Reforço (1969), Ciência e Comportamento Humano (1953) e O Comportamento Verbal (1957).

O capítulo de Borloti (2005) intitulado Abstração, metáfora, sonho e inconsciente: uma interpretação skinneriana, por propor-se a tratar especificamente do assunto do inconsciente no campo da clínica comportamental, foi o texto consultado para verificar o tratamento conferido pelo terapeuta analista comportamental ao tema. O livro de Kohlenberg e Tsai (1991), Functional Analytic Psychotherapy: creating intense and curative therapeutic relationships, foi outra importante referência para interpretar a postura do clínico em relação ao insconsciente.

O artigo de Strapasson, Carrara e Lopes (2007), por discutir especificamente essa questão, apoiou a primeira seção do artigo, a qual justifica a necessidade de tratar termos oriundos de outras tradições teóricas. O livro de Abib (2007) foi examinado e a sistematização da noção de inconsciente proposta foi descrita na terceira parte do presente artigo.

\footnotetext{
Este artigo foi resultado de algumas reflexões dos autores na ocasião do I Simpósio de Psicologia do Inconsciente realizado em Curitiba nos dias 1 e 2 de novembro de 2008, em que houve uma seção sobre o Inconsciente na Análise do Comportamento.
}

\section{1. É Necessário Falar sobre o Inconsciente na AC?}

Preliminarmente, pode-se indagar se há a necessidade de falar sobre o inconsciente na AC. Strapasson, Carrara e Lopes (2007) escreveram um artigo intitulado Conseqüências da interpretação funcional de termos psicológicos. O artigo indica três consequências principais da tradução de termos psicológicos.

(...) 1) aumentar a disseminação da AC e suas chances de sobrevivência enquanto prática cultural; 2) rever, desafiar e aprimorar aspectos teóricos e metodológicos da filosofa behaviorista radical, da análise experimental do comportamento e da análise aplicada do comportamento, com implicações para as tecnologias derivadas dessas três áreas e, por fim, 3) criar recursos para o ensino da AC e áreas afins (Strapasson, Carrara e Lopes, 2007, p. 79).

De acordo com os autores, as disciplinas científicas contribuem na produção de conhecimento sobre o comportamento útil se aumentam a possibilidade de sua predição e controle. O presente artigo inspira-se nas possíveis utilidades sugeridas por Strapasson, Carrara e Lopes (2007) da iniciativa de debruçar sobre termos tratados por outras tradições em Psicologia, como é o caso do Inconsciente.

\section{Pode-se Falar sobre o Inconsciente na AC?}

A segunda questão relevante para o tratamento do tema do inconsciente pela AC é a capacidade da mesma em tratar o termo psicológico 'inconsciente’.

Strapasson, Carrara e Lopes (2007, p. 76-77) afirmam que Skinner assumiu, basicamente, duas posições ao longo de sua obra sobre a capacidade da AC em lidar com termos psicológicos estrangeiros, isto é, oriundos de outras teorias psicológicas ou do senso comum.

De acordo com Strapasson, Carrara e Lopes (2007, p. 76-77), a primeira postura pode ser descrita como eliminativista, uma vez que Skinner advoga o abandono de termos aparentemente incompatíveis com sua proposta de ciência do comportamento. A segunda postura pode ser demarcada pela exposição formal sobre a interpretação dos termos psicológicos por ocasião do simpósio sobre operacionalismo, organizado por Boring, em 1945. Ao adotar essa postura, Skinner se opõe ao operacionalismo clássico e defende uma análise estritamente funcional do comportamento verbal, em que o signifcado dos termos psicológicos poderia ser verificado em termos de identifcação de contingências.

Conforme a segunda postura, a tradução dos termos psicológicos define-se pela identifcação e análise das contingências que levam à proposição dos conceitos. Um projeto dessa natureza não produz traduções fiés de ter- 
mos da linguagem cotidiana ou psicológica para termos comportamentais. Skinner indica que a tradução de um termo mental modifica o sentido do termo original e defende que não seria sábio propor definições exaustivas dos sentidos originalmente atribuídos aos termos mentais (1974, p. 17-18).

Vale lembrar nesse ponto também o tratamento dado por G. Ryle (1970) ao uso de certos termos psicológicos. Ryle considerou-os derivados de erros categoriais advindos da adoção de um esquema geral no qual se admite que espírito/mente e corpo são entidades de naturezas distintas.

Como corolário necessário deste esquema geral, está implìcitamente indicada uma maneira especial de interpretar os nossos conceitos vulgares de faculdades e operações mentais. Os verbos, substantivos e adjetivos com os quais na vida normal descrevemos a compreensão, carácter e acções de mais alto nível das pessoas com quem contactamos, devem ser interpretados como significando episódios especiais das suas histórias secretas ou como tendências significativas para que tais epsisódios ocorram. Quando se descreve alguém como sabendo, acreditando ou julgando alguma coisa, esperando, receando, planeando ou evitando qualquer coisa, projectando isto ou divertindo-se com aquilo, supõe-se que estes verbos indicam a ocorrência de modificações específicas na sua (para nós) oculta corrente de consciência (p. 15).

O presente artigo vai ao encontro da segunda postura, ao debater o termo inconsciente; que é discutido com ênfase no contexto da clínica analítico-comportamental. Usaram-se, para tanto, os exemplos e definições apresentados por Skinner e a sistematização de inconsciente proposta por Abib (2007).

\section{O Que é o Inconsciente para a AC?}

Tendo sido tratada a necessidade, a justificativa e a possibilidade para se falar sobre o inconsciente na AC, pode-se agora inquerir sobre qual é o estatuto que este problema assume na AC.

Em seu livro Sobre o Behaviorismo, Skinner (1974/1982) posiciona-se sobre a questão do inconsciente na AC:

Diz-se amiúde, particularmente os psicanalistas, que o behaviorismo não pode haver-se com o inconsciente. $\mathrm{O}$ fato é que, para começar, ele não se avém com outra coisa. As relações controladoras entre o comportamento e as variáveis genéticas e ambientais são todas inconscientes, uma vez que não são observadas (Skinner, 1974/1982, p. 133).

A objeção que o Behaviorismo Radical impõe ao inconsciente é a mesma que apresenta a qualquer outro evento interno como agente do comportamento individual: "O que o behaviorismo rejeita é o inconsciente como um agente, e está claro que também rejeita a mente consciente como um agente" (Skinner, 1974/1982, p. 133).

O Behaviorismo Radical indica o erro categorial, conforme proposto por Ryle (1970), cometido ao substantivar ações que são designadas com os nomes "inconsciente" ou "inconsciência". "Tendemos a transformar em substantivos, adjetivos e verbos e devemos, em seguida, encontrar um lugar para as coisas supostamente representadas pelos substantivos" (Skinner, 1974/1982, p. 139). Nesse aspecto, é importante perceber que a principal oposição do comportamentalismo não se refere à utilização de termos psicológicos estrangeiros, mas às explicações e relações causais dos supostos agentes mentais.

Feitas essas considerações, pode-se admitir que o Behaviorismo Radical preocupa-se com o inconsciente e assume que todo comportamento é originalmente inconsciente.

\subsection{Duas Condições para o Inconsciente na Análise do Comportamento}

De acordo com a AC, há duas condições principais nas quais o termo inconsciente é empregado por certas tradições teóricas em Psicologia, em especial a psicanálise freudiana. Ambas as condições dependem de um ambiente social e verbal que promove a aprendizagem de comportamentos autodescritivos e que ensina também uma classe de fuga/esquiva de tais descrições (Skinner, 1974/1982). A primeira condição refere-se à inconsciência devida à falta de exposição a um ambiente verbal gerador de conhecimento sobre o que se fez, o que se está fazendo, o que se tende a fazer ou sobre as variáveis controladoras de um dado comportamento (Skinner, 1953/1981). Uma segunda condição em que o termo inconsciente é usado está mais estreitamente ligada ao que as certas teorias psicológicas chamariam de inconsciente reprimido e diz respeito à exposição à contingências punitivas (Skinner, 1957/1978). Na clínica analítico- comportamental, as duas condições são analisadas (Borloti, 2005), mas grande ênfase é dada à segunda, ou seja, àquela que produz uma classe de fuga/esquiva de tatear comportamentos puníveis.

Conforme a primeira condição, segundo Skinner (1953), são quatro as formas pelas quais o autoconhecimento pode estar ausente: 1 . não saber que fez alguma coisa; 2. não saber que está fazendo algo; 3. não saber que tende a fazer alguma coisa; 4 . não saber quais são as variáveis controladoras do seu comportamento.

Em 1953, quando Skinner descreveu tais condições, ilustrou-as com situações que não eram clínicas, necessariamente. Borloti (2005) ofereceu exemplos na clínica analítico-comportamental daquelas quatro condições. Tentar-se-á fazer o mesmo aqui. 
No contexto da clínica, é comum que o cliente não saiba que fez alguma coisa nos seus relacionamentos afetivos mal-sucedidos. Muitas vezes o cliente não sabe que o que fez afastou seus pares afetivos. Uma cliente, artista plástica, levou um tempo da terapia até ficar consciente de que afastava os rapazes interessados em envolver-se com ela, impedindo que eles se aproximassem. Ela punia os comportamentos deles mais iniciais de aproximação. Toda essa classe do comportamento da cliente era mantida por variáveis do contexto familiar, como a tarefa de acompanhar sua mãe e suprir deficiências afetivas do relacionamento dos pais.

Um exemplo de uma condição na qual o cliente não sabe que está fazendo alguma coisa é seu comportamento na relação com o terapeuta. Frequentemente, o cliente não sabe que está fazendo com o terapeuta, precisamente o que faz com outras pessoas fora do contexto da sessão. Uma cliente atendida pela primeira autora emitia verbalizações arrogantes, falando de suas forças e vantagens e evitando falar de suas fraquezas sempre que o tema sinalizava a possibilidade de ela descrever ou entrar em contato com eventos aversivo. A terapeuta perguntou "Como foi o encontro com Rafael? Você parecia animada com esse compromisso na última sessão..." Carina disse "É difícil achar alguém à minha altura nessa cidade. Fiquei com ele, mas ele não era importante. Acho o modo como se veste muito cafona." Terapeuta: "Vocês se falaram depois de terem saído?" Carina: "Não. Claro que não. Ele não me ligou porque sabia que eu não estava interessada." Terapeuta: "E o que você sentiu?" Carina: (Olhando de modo a desafiar a terapeuta) "Nada. Eu não perco tempo com essas coisas tolas" (como a pergunta da terapeuta). Eu estou realmente acima disso." A terapeuta mostraria então que aquele modo de se comportar, era aversivo para o outro, que tenderia a se afastar. A terapeuta reforçaria diferencialmente com afeto, aceitação e respeito as respostas de admitir fraquezas. A fuga/esquiva das condições de desvantagem era mantida porque as respostas com certa mediocridade ou normalidade eram punidas pela mãe da cliente. A cliente tornou-se consciente disso ao longo da terapia.

O cliente pode ainda não saber que tende a fazer alguma coisa. Débora disse em uma sessão que estava apenas indo ao clube, que, por coincidência, era frequentado pelo amante, de quem achava que estava se afastando. A primeira autora, terapeuta da cliente, discutiu isso, descrevendo a probabilidade de emissão de respostas de procurar o ex- amante.

O cliente pode ainda não saber quais as variáveis controladoras de seu comportamento. Uma cliente não entendia por que se mantinha em um namoro no qual se sentia frustrada, desrespeitada e sem perspectiva de se sentir melhor. Depois de muitas sessões de tratamento, a cliente relatou que seus pais puniam seus relatos de estar só ou com um outro namorado. Seus pais reforçavam negativamente o manter-se no relacionamento e tais variáveis eram predominantes às variáveis do próprio relacionamento.

\subsection{A Exposição à Punição e o Surgimento Virtual- mente Automático da Classe de Fuga/Esquiva: a Segunda Possibilidade de Inconsciência}

Até esse ponto, discutiu-se a consciência ou a inconsciência gerada por exposições ou falta de exposições a uma comunidade verbal. Daqui para adiante, serão considerados os comportamentos autodescritivos falhos ou recolhidos dada a exposição à punição, a qual gera automaticamente uma classe de fuga/esquiva.

"Em 1953 e 1957, Skinner analisou fenômenos comportamentais como atos falhos, fantasias, criatividade, humor, metáfora e sonhos." (Borloti, 2005, p. 73).

Muitos desses fenômenos referem-se a comportamentos mantidos sob controle aversivo. Eles têm estreita relação com o que a literatura chama de "repressão" ou de "inconsciente reprimido".

Além disso, em seu livro Contingências do Reforço, Skinner (1969) nota a diferença entre as duas formas de inconsciente e afirma:

O inconsciente de Freud não era, entretanto, simplesmente o comportamento do qual uma pessoa não se tinha tornado consciente. Ele enfatizou razões especiais pelas quais o comportamento autodescritivo pudesse faltar. Algumas das contingências mais poderosas, dispostas pela comunidade para gerar consciência, envolvem punição. Censurar alguém é atribuir consequências aversivas a seu comportamento. A afirmação "você fez isto!" assevera uma ligação entre o comportamento (o que a pessoa fez) e consequências indesejáveis (isto). Observa- se ao acusado que observe a ligação causal. Como resultado, um comportamento similar ou tendo consequências similares poderá gerar estímulos condicionados aversivos, sentidos possivelmente como culpa ou vergonha. Freud argumentou que são as consequências punitivas que reprimem a autodescrição ou consciência. As contingências continuam eficazes, mas não são notadas (1980, p. 358).

Um outro aspecto fundamental a ser considerado é que a operação de punição sobre uma dada resposta, instala automaticamente uma classe de fuga/esquiva. As respostas cujo efeito será o de adiar ou evitar o evento aversivo da punição são fortalecidas e reforçadas negativamente. De acordo com Skinner (1953), diversos comportamentos bizarros ou excêntricos podem ser explicados desse modo. Entretanto, muitas vezes, essas respostas não são verificadas tão facilmente. Parece que o organismo está sem fazer nada. É caso das respostas de permanecer imóvel e quieto. As respostas de calar-se, de desviar o 
olhar, de abaixar a cabeça, de pensar de modo confuso, de falar pouco, de gaguejar, de hesitar etc. Elas são um modo de esquivar-se passivamente de algum aversivo e enganam o observador descuidado, que tende a julgar que a punição diminuiu a frequência de um responder e que nenhum outro responder está em curso. O clínico trabalha frequentemente com esse responder menos óbvio à observação.

As vezes é necessário (...) encarar o 'fazer nada' como uma resposta, se isso tiver consequências reforçadoras identificáveis. Mas 'fazer nada' é obviamente incompatível com um comportamento punível e, entre as consequências do não falar, está frequentemente a evitação da punição (Skinner, 1957/1978, p. 454).

Muitas respostas, podem, então ser rejeitadas como fuga/esquiva de algum evento aversivo. Segundo Skinner (1957/1978, p. 446):

(...) a punição não enfraquece diretamente o comportamento; ela apenas fortalece formas incompatíveis. (...) quando a resposta torna a ser fortalecida até o ponto de emissão, ela gera uma estimulação aversiva (a 'ameaça' de punição). Essa consequência especial altera a aparente força operante verbal, mas tem outro efeito distinguível ao gerar um tipo de comportamento convenientemente chamado rejeição. Rejeitar uma resposta reduz a estimulação aversiva condicionada gerada por ela e é reforçada por isso. O comportamento deve ser classificado quer como fuga quer como evitação dependendo do fato da estimulação aversiva condicionada já ter ocorrido.

Uma outra forma de responder fugindo/esquivandose de algum aversivo é o uso de símbolos, das metáforas e, em alguns casos, do sonhar (Borloti, 2005). Segundo Skinner (1953/1981, p. 280): “(...) Pode aparecer uma resposta que obtenha reforço ao mesmo tempo em que evita punição". O autor exemplifica esse tipo de comportamento quando se contempla o nu na arte, em vez de ver pornografia. Ainda de acordo com Skinner (1953/1981, p. 280) "Na fantasia, o indivíduo faz uma adaptação semelhante entre ver certos objetos ou padrões e evitar a estimulação aversiva. Devaneia em uma dada área, mas de um modo tal que não gere muita culpa." O símbolo, segundo Skinner (1953/1981, p. 280) “(...) é qualquer padrão temporal ou espacial que seja reforçador em razão da semelhança com outros padrões, mas que escape de punição por causa das diferenças."

Diz Skinner:

Freud conseguiu demonstrar certas relações plausíveis entre sonhos e variáveis na vida do indivíduo. A presente análise essencialmente concorda com sua interpretação. Os indivíduos estão fortemente inclinados a emprenharem-se em comportamentos que alcançam reforços, como contato sexual ou imposição de danos sobre outros. Essas espécies de comportamento, contudo, são precisamente o tipo com maior probabilidade de ser punido. Disso resulta que o indivíduo apenas não se empenha abertamente no comportamento, mas não pode se empenhar cobertamente, ou se ver encobertamente empenhado sem estimulação aversiva automática (Skinner, 1953/1981, p. 281).

Os sonhos são comportamentos operantes do tipo ver na ausência da coisa vista (Skinner, 1974/1982). As respostas desse operante podem ganhar a mesma funcionalidade que as emitidas na arte, na metáfora ou nos símbolos, assim, ao sonhar, a pessoa pode ver certos objetos ou padrões apetitivos, enquanto evita estimulação aversiva.

As contingências punitivas de comportamentos verbais e não verbais geram estimulação aversiva. A punição pode ser contingente ao comportamento de conhecer comportamentos puníveis, ou seja, à emissão de respostas verbais vocais ou não vocais a tais comportamentos. Nesse caso, a pessoa experimentará uma estimulação aversiva condicionada e emitirá comportamentos de fuga/ esquiva que podem ser mais flagrantes, como por exemplo, a emissão de comportamentos excêntricos ou bizarros. Ou, podem ser muito sutis e de difícil identificação. É o caso de ficar quieto ou de responder simbolicamente aos eventos na arte, nos sonhos, nas metáforas etc.

(...) a punição torna aversivos os estímulos gerados pelo comportamento punido. Qualquer comportamento que reduza aquela estimulação é em consequência, automaticamente reforçado. Agora, entre os tipos de comportamento com maior probabilidade de gerar estímulos condicionados aversivos como resultado da punição está o comportamento de observar o ato punido ou de observar a ocasião para o ato ou qualquer tendência de executá-lo. Como resultado da punição não apenas nos empenhamos em outros comportamentos que excluam as formas punidas, mas empenhamo-nos também em comportamentos que excluem o tomar conhecimento do comportamento punido (Skinner, 1953/1981, p. 278).

Como, na psicoterapia de adultos, muitos eventos relevantes da sessão podem ser identificados nas verbalizações emitidas pelo cliente, convém analisar mais detalhadamente o efeito da punição sobre o comportamento verbal, sobretudo, em uma parte dele que é a verbalização.

\subsection{A Punição do Comportamento Verbal}

O efeito da punição sobre o comportamento verbal pode ser observado na retratação ou na retração (Skinner, 1957). Os clínicos estão especialmente treinados para 
observar retratações e retrações no comportamento verbal de seus clientes. Segue um exemplo de retratação na verbalização de Márcia. Depois de ter relatado o quanto sua mãe havia lhe oprimido e punido seus comportamentos de diversão e de busca de um parceiro afetivo no fim de semana, Márcia diz "Quero deixar bem claro que amo a minha mãe. Tudo que ela faz é para meu bem. Se ela age assim, é para me proteger. Eu deveria ser uma fiIha mais agradecida." A terapeuta então pergunta “O que teria acontecido se você simplesmente não tivesse atendido sua mãe ao celular (e então retornado para casa)... mas, permanecido no barzinho com suas amigas?" Ao que Márcia responde com a verbalização "Ah...Não sei... Sei lá...Acho que...Talvez ela...Ou talvez eu...Bem, hoje estou meio confusa".

Outro efeito da punição sobre determinados aspectos do comportamento verbal resulta no que a psicanálise chama de racionalização. Skinner, em 1953, ilustrou a fuga/esquiva de conhecer um comportamento punível, mantendo a inconsciência das variáveis controladoras daquele comportamento. Tratavam-se das justificativas comumente dadas pelos adultos de por que bateram em uma criança. Se um adulto disser "Bati mesmo! Aproveiteime do fato de ser maior que ela e me vinguei!", sofreria reprimendas. Essa é uma verbalização de descrição de um comportamento punível e seria seguida de punição. Então, os adultos tendem a dizer "Eu apliquei o castigo para o bem da criança. Bati para que ela aprendesse o jeito correto de fazer as coisas." Ao racionalizar assim, evita a punição.

\subsection{A Autocorreção: a Rejeição do Comportamento Verbal e Inconfessável a si Próprio}

Na autocorreção do comportamento verbal, uma sequência de rejeições feitas pela pessoa, que é, a um só tempo, falante e é ouvinte de si mesma levará a condições muito especiais, sobretudo, para entendimento do clínico: o inconfessável para si mesmo.

Algumas respostas podem ser apresentadas ou rejeitadas dependendo de seu efeito sobre o falante ou sobre o ouvinte. Considerando que uma pessoa pode ser falante e ouvinte de si mesma, ela apresenta e rejeita respostas verbais para si. Uma resposta pode ser lembrada ou anulada por uma resposta adicional e como já foi dito, a retração e a retratação são formas de responder em circunstâncias nas quais o comportamento verbal é punível.

Skinner (1957/1978, p. 443) apresenta uma sequência de processos de rejeição do comportamento verbal, iniciando pelas mais facilmente observáveis, que são as correções feitas no papel por um escritor, e terminando nas possibilidades mais imperscrutáveis, como quando o falante não confessa algo nem a si mesmo.
Segundo Skinner, os críticos literários examinam como um autor fez suas correções no momento da composição. "A maior parte das correções de Keats foi feita no momento da composição; uma palavra era rejeitada antes mesmo de ser totalmente escrita." (Ridley apud Skinner, 1957/1978, p. 443). Então, diz Skinner, que uma correção comparável do comportamento vocal é mais efêmera. O comportamento subvocal, a seu turno, pode ser revogado antes de ser emitido de forma audível. E, finalmente, uma resposta verbal pode ser rejeitada antes de uma emissão subaudível.

De acordo com Skinner (1957/1978, p. 445) “(...) a estimulação associada com a produção do comportamento verbal é suficiente para capacitar alguém a rejeitar uma resposta antes que essa resposta tenha assumido sua forma final."

Em seguida, Skinner (1957) explica por que uma resposta é rejeitada. Ela é rejeitada porque foi punida pelo ouvinte. Então, Skinner descreve as condições que levam o ouvinte a punir respostas. Ele tende a punir quando as respostas desagradam-no com barulho; quando oferecem a ele um controle de estímulo deficiente; quando apresentam coisas desagradáveis para o ouvinte.

O clínico dedica-se de modo especial a essa última condição. A prática clínica indica que, em geral, os ouvintes nas famílias dos clientes punem normalmente suas verbalizações sobre seu desempenho insatisfatório, sobre seu desejo, quando este é diferente do de outro membro da casa, ou sobre suas falhas na execução de tarefas.

A punição acaba por produzir determinados efeitos no comportamento do falante, segundo Skinner (1957). Ele pode disfarçar sua identidade, pode recolher a resposta para o encoberto, pode falar sozinho ou por meio de uma fala disfarçada. Um exemplo pode ser dado com a letra da música de Cazuza "Eu protegi seu nome por amor, com o codinome beija-flor."

Skinner (1957) lista alguns autoclíticos da correção do comportamento verbal. A paralepsis é um deles e pode ser ilustrada com a fala hilária do personagem Pinóquio no filme Shrek 3. Seria punível a revelação do paradeiro do Shrek, mas era também punível calar-se diante do príncipe, que o questionava coercitivamente, ameaçando sua vida. Então Pinóquio diz algo como "não estou absolutamente certo de onde provavelmente o Shrek não está! Com alguma incerteza eu sei onde ele estaria..."

Outro autoclítico comum é iniciar alguma verbalização, pedindo desculpas, dizendo 'Com o perdão da palavra.... A risadinha nervosa anula alguma propriedade punível do que está sendo dito. A baixa modulação da voz, o deslocamento, verificado quando o cliente fala de um assunto "para” não falar de outro ou, simplesmente o permanecer quieto são, segundo Skinner (1957), autoclíticos relacionados à correção do comportamento verbal. 


\subsection{Uma Sistematização do Inconsciente}

Uma sistematização do inconsciente na AC e fundamentada na obra de Skinner, pode ser encontrada no ensaio psicológico O Sujeito no Labirinto (Abib, 2007). Nesse ensaio, Abib (2007) indica a importância do comportamento verbal para a compreensão do sujeito psicológico conforme o Behaviorismo Radical. O comportamento verbal é definido como todo comportamento que é modelado e mantido por consequências mediadas, ou que é efetivo somente com a mediação de outras pessoas.

Neste ensaio, Abib (2007, p. 35-37) afirma que os comportamentos não-verbais são comportamentos inconscientes, mas que também há comportamentos inconscientes que são verbais. Comportamentos inconscientes podem ser não-verbais e verbais não-vocais e são diferentes dos comportamentos conscientes por estes serem verbais vocais.

Além disso, Abib indica um caminho de interpretação analítico-comportamental para a cognição inconsciente:

(...) o comportamento não-verbal é cognitivo: produz consequências efetivas de sobrevivência. O comportamento verbal não-vocal também é cognitivo: produz consequências reforçadoras. Há, então, nessas duas versões de comportamentos inconscientes, cognição inconsciente. Com base na noção de comportamento inconsciente, pode-se tomar a cognição inconsciente como sendo equivalente ao inconsciente cognitivo. Isso significa dizer que há uma série de equivalências que explicam o inconsciente cognitivo à cognição não-verbal ou verbal não-vocal (2007, p. 36).

Do mesmo modo, Abib sinaliza a diferença entre as duas formas de inconsciente cognitivo e de como elas podem gerar sofrimento.

Uma das versões mais divulgadas do inconsciente cognitivo é o inconsciente reprimido. O inconsciente reprimido refere-se a comportamentos submetidos a um processo conflitante de punição e reforço. (...) $\mathrm{O}$ conhecimento que existe no inconsciente reprimido tem suas características peculiares. Por exemplo, não é possível afirmar que o comportamento sexual é efetivo da mesma maneira no inconsciente cognitivoreprimido e no inconsciente cognitivo-não-reprimido. No inconsciente cognitivo-reprimido, a efetividade da cognição é realizada no contexto de uma clandestinidade que não se verifica no inconsciente cognitivo-não reprimido. Trata-se, enfim, de formas distintas de efetividade inconsciente do comportamento sexual. No inconsciente reprimido as contingências punitivas desempenham papel preponderante. A pessoa sente estímulos aversivos condicionados produzidos pela emissão que comportamentos que foram punidos, e foge ou se esquiva deles. A comunidade verbal descreve os sentimentos produzidos por esses estímulos atribuindo-lhes nomes como vergonha ou culpa. Nem por isso, nem por terem um nome e uma descrição a pessoa toma consciência desses sentimentos ou é capaz de alterá-los. (...) Mas a tarefa não é simpres porque os comportamentos de fuga e de esquiva dificultam a tomada de consciência seja das contingências e dos estímulos aversivos condicionados produzidos pela emissão do comportamento punido, ou dos sentimentos controlados por tais contingências e estímulos. Trata- se de uma situação desoladora porque o comportamento não aparece para a comunidade verbal e ela não tem como ensinar a pessoa a tomar consciência das contingências, dos comportamentos e sentimentos (2007, p. 36-37).

A explicação que Abib oferece acerca do inconsciente reprimido sugere o quanto esse tipo de comportamento tende a provocar sofrimento. A dificuldade de eliminar o sofrimento advém da impossibilidade de exposições a novas condições capazes de ensinar a descrição das contingências, inviabilizando a tomada de consciência dela. Isso diminui muito a chance de mudança comportamental e de alívio do sofrimento.

Considerando isso, a questão a seguir relaciona-se com as possibilidades de tratamento clínico de sofrimento originado por problemas de "inconsciência".

\section{4. o Inconsciente é Tratado no Contexto Clínico em $\mathrm{AC}$ ?}

Conforme a definição do inconsciente nas seções anteriores, cabe agora investigar quais são as possibilidades de seu manejo na clínica comportamental. A primeira forma de manejo na clínica pode ser descrita como a promoção do autocontrole, por meio do conhecimento ou identificação de variáveis controladoras do comportamento.

Skinner (1974) analisa os usos do termo conhecer. O conhecer é um termo empregado para designar o estar em contato com, o ser íntimo de; o ser capaz de; o possuir várias formas de comportamento em relação a. Usase também o termo conhecer ou saber indicando "estar sob o controle de".

As contingências verbais podem então, produzir um eu cognoscente e um eu conhecido. Isto é, pode-se conhecer a si mesmo, respondendo ao seu próprio comportamento. Skinner afirma que todas as espécies, exceto a humana, comportam-se sem saber que o fazem. Em algum estágio da história da espécie humana surge uma comunidade verbal que faz perguntas acerca do comportamento e, com isso, gera comportamento autodescritivo. 
Uma pessoa se torna consciente em um sentido diferente quando uma comunidade verbal arranja contingência sob as quais ela não somente vê um objeto, mas 'vê' que ela o está vendo. Em um sentido especial, consciência é um produto social. (Skinner, 1974, p. 220)

\section{Assim, diz Skinner}

O conhecimento de si próprio tem origem social e é inicialmente útil para a comunidade que propõe perguntas. Mais tarde, torna-se importante para a própria pessoa - por exemplo, para haver-se consigo mesma ou para controlar-se (Skinner, 1974/1982, p. 146).

O autoconhecimento pode ser gerado por comunidades verbais distintas conforme a utilidade para cada uma dessas comunidades.

Diferentes comunidades geram tipos e quantidades diferentes de autoconhecimento e diferentes maneiras de uma pessoa explicar-se a si mesma e aos outros. (...) Certas comunidades produzem pessoas particularmente cônscias de suas reações à arte, música ou literatura; outras, de suas relações com aqueles que as cercam (Skinner, 1974/1982, p. 146).

A Psicologia constitui-se em uma dessas comunidades geradoras de um tipo especial de autoconhecimento. Trata-se do autoconhecimento relativo às relações com os outros.

Em todas essas condições, o terapeuta procura gerar consciência no repertório verbal do cliente. Entretanto, o cliente pode aprender a descrever o seu próprio comportamento sem que isso garanta a mudança clínica. Ou seja, a consciência, como comportamento autodescritivo, não provoca uma mudança automática em outros comportamentos. Descrever seu próprio comportamento é apenas um comportamento verbal relacionado a outro comportamento. A mudança depende de alterações eficazes de contingências. Quando alguém está submetido à terapia, supõe-se que fará, ele próprio, alterações nas contingências que afetarão seu comportamento, isto é, que exercerá autocontrole. A consciência é um requisito para o autocontrole.

A FAP ajuda a promover auto-observação, autocontrole e autoconhecimento, oferecendo uma apropriada sistematização de procedimentos para o clínico manejar a classe de fuga/esquiva gerada na história de vida do cliente e, com isso, propõe um modo de manejar fenômenos inconscientes no contexto da sessão.

A FAP sistematiza o comportamento do cliente no contexto da sessão em três classes de resposta. O comportamento clinicamente relevante CRB1, classe de fuga/ esquiva relacionada ao problema clínico do cliente, portanto, mantida por reforço negativo. O CRB2, uma classe concorrente com a primeira e cuja pouca força relacionase ao problema do cliente. E, finalmente, o CRB3, uma classe de descrição de variáveis controladoras do comportamento. Portanto, o CRB 3 refere-se à consciência do cliente. $\mathrm{O}$ terapeuta constitui-se em uma comunidade verbal especial para gerar autoconhecimento relacionado aos três tipos de CRB. Remetemos o leitor ao livro de Kohlenberg e Tsai (1991) para compreender em detalhes como a classe de fuga/esquiva pode ser manejada pelo clínico. De modo geral, o terapeuta reforça diferencialmente as classe de CRB 2 e 3, extinguindo ou punindo com confrontações o CRB1. Interpretações sobre o comportamento do cliente são oferecidas pelo terapeuta no aqui/agora da sessão.

Em seu livro Contingências de reforço, Skinner (1969/1980) resume sua postura diante do problema do insconsciente:

Não estamos de jeito nenhum sempre conscientes do que fazemos ou do por quê. (...) O (psicólogo) comportamental ouve frequentemente "E o inconsciente?" como se lhe apresentasse um problema especialmente difícil, mas o único problema é a consciência. Todo comportamento é basicamente inconsciente no sentido em que é modelado e mantido por contingências que são eficazes mesmo quando não são observadas ou analisadas de outra forma. Em algumas culturas, incluindo a nossa, práticas bem estabelecidas de autodescrição geram consciência no presente sentido. Não só nos comportamos, como observamos que estamos nos comportando, e observamos as condições sob as quais nos comportamos (1980, p. 358).

Portanto, Skinner (1969/1980) nesse comentário sugere a importância da comunidade verbal geradora de autodescrição e por meio disto, da consciência. Em suma, trata-se precisamente da preocupação e da atividade central do clínico em AC.

\section{Considerações Finais}

Foram apresentadas no presente artigo, algumas reflexões sobre o Inconsciente na Análise Comportamental Clínica. 1. A análise comportamental debruça-se sobre o inconsciente, isto é, sobre a falta de comportamentos de auto-observação e de autodescrição e sobre a falta do relato de variáveis controladoras. 2. O inconsciente e o consciente não são agentes do comportamento, são, isto sim, mais comportamentos a serem explicados. 3. A comunidade verbal é que, inicialmente, gera os comportamentos auto-descritivos, porque são importantes para ela e depois, tornam-se importantes para a própria pessoa. 4. A comunidade verbal produz o eu cognoscente e o eu conhecido. 5. A pessoa pode não descrever seu comportamento por jamais ter sido exposta a uma comunidade 
verbal para ensiná-lo ou não descreve e não olha para ele porque o descrever, o olhar e/ou o próprio comportamento descrito foram punidos. 6. A comunidade verbal pune alguns comportamentos do falante, acarretando estimulação aversiva e o comportamento verbal autodescritivo de comportamentos punidos é acompanhado de estimulação aversiva condicionada. 7. A punição estabelece padrões operantes de fuga/esquiva, sobre os quais incidirão as intervenções clínicas (O CRB1). 8. Diversas respostas sob controle aversivo relacionam-se a atos falhos, símbolos, sonhos, repressão etc. 9. O terapeuta promove autoconhecimento ou consciência, que serão terapêuticos somente se possibilitarem autocontrole, tomada de decisão e resolução de problemas. Sendo assim, a promoção de consciência é focada no CRB1 e 2 e seu manejo requer várias sessões do tratamento.

\section{Referências}

Abib, J. A. D. (2007). O sujeito no labirinto: um ensaio psicológico. Santo André: ESEtec.

Borloti, E. B. (2005). Abstração, metáfora, sonho e inconsciente: uma interpretação skinneriana. Em: E. B. Borloti, S. R. F. Enumo, \& M. L. P. Ribeiro (Orgs), Análise do Comportamento: Teorias e práticas (p. 69- 96). Santo André: ESETec.

Kohlenberg, R. J., \& Tsai, M. (1991). Functional Analytic Psychotherapy: creating intense and curative therapeutic relationships. Nova York: Plenum press.

Ryle, G. (1970). O conceito de espírito (M. L. Nunes, Trad.). Lisboa: Moraes. (Originalmente publicado em 1949).

Skinner, B. F. (1981). Ciência e comportamento humano. São Paulo: Martins Fontes Editora. (Originalmente publicado em 1953).

Skinner, B. F. (1980). Contingências do Reforço. Coleção Os Pensadores. São Paulo: Abril Cultural. (Originalmente publicado em 1969).

Skinner, B. F. (1978). A auto-correção. Em: B. F. Skinner, $O$ Comportamento Verbal (p. 443- 458). São Paulo: Cultrix. (Originalmente publicado em 1957).

Skinner, B. F. (1982). Sobre o behaviorismo. São Paulo: Cultrix/ Edusp. (Originalmente publicado em 1974).

Strapasson, B. A., Carrara, K., \& Lopes Jr, J. (2007). Conseqüências da interpretação funcional de termos psicológicos. Revista Brasileira de Terapia Comportamental e Cognitiva, 9, 73-85.
Jocelaine Martins da Silveira - Graduada em Psicologia pela Universidade Federal do Paraná, Especialista em Psicoterapia na Análise do Comportamento, Mestre em Psicologia Experimental pela Universidade de São Paulo e Doutora em Psicologia Clínica pela Universidade de São Paulo. É professora adjunta no Departamento de Psicologia da Universidade Federal do Paraná (UFPR) onde atualmente exerce a função de vice-coordenadora do Programa de Mestrado em Psicologia e desenvolve estudos e orientações no campo da Análise Comportamental Clínica. Endereço para correspondência: Departamento de Psicologia, Universidade Federal do Paraná, Praça Santos Andrade, $\mathrm{n}^{\circ}$ 50, sala 215 (Ala Alfredo Buffren). CEP 80.060.240 - Curitiba, PR. Email: jocelainesilveira@ufpr.br

Lázaro de Almeida - Psicólogo, Consultor Organizacional e Pesquisador da empresa iApex - Gestão do Conhecimento e Mestrando em Psicologia Clínica pela Universidade Federal do Paraná. Endereço para correspondência: iApex Gestão do Conhecimento. Rua Mário Mendes de Lara, $\mathrm{n}^{\circ} 644$ (Uberaba) - CEP 81.570-200, Curitiba, PR. Email: lazaro@iapex.com.br 